\title{
B chromosome polymorphism in Korean rye populations
}

\author{
F. Romera, \\ J. M. Vega, \\ M. Diez and \\ M. J. Puertas
}

Departamento de Genética, Facultad de Biología,

Universidad Complutense, 28040 Madrid, Spain

Four Korean rye populations with B chromosomes at frequencies ranging from 15 to 55 per cent have been analyzed in two successive generations in a field experiment. B chromosome frequencies were maintained in spite of the environmental change from Korea to Madrid. Values of variables with effect on viability and fertility have been estimated in plants with and without Bs, in both generations. B chromosomes did not affect viability, while fertility decreased when the number of Bs increased. Our data are against an adaptive nature of $B$ chromosomes.

First pollen mitosis was observed in $2 \mathrm{~B}$ plants. The frequency of metaphases with $1 \mathrm{~B}$ and the rate of nondisjunction at anaphase were high and similar in all populations. Since the decrease of fertility due to Bs and the cytological behaviour of Bs at gametogenesis were similar in all populations, the balance between these two factors cannot account for the establishment of equilibria at different frequencies.

\section{INTRODUCTION}

B chromosomes are widely distributed in rye populations. High frequencies of Bs are found in Korea (Müntzing, 1954, 1957a, b). Lee $(1963,1966,1976$, $1981)$ and Lee and Min $(1965,1966,1968)$ reported a variation in B chromosome frequencies among Korean populations which was not related to any geographic or ecological cline.

Rye B chromosomes tend to increase in number by nondisjunction during both male and female gametogenesis (Müntzing, 1946; Håkanson, 1948). Most authors believe that this tendency to accumulation is enough to compensate for the selection against individuals carrying a high number of $B$ chromosomes, thereby maintaining the B chromosome polymorphism in spite of the low fitness of carriers.

The purpose of this work is to study whether stable polymorphisms are established at different frequencies of $\mathrm{B}$ chromosomes, and to analyse the causes of their maintenance.

The results are discussed in relation to the adaptive nature of $\mathrm{B}$ chromosomes.

\section{MATERIAL AND METHODS}

Four Korean populations of Secale cereale have been used: Gumsan 3, Gumsan 4, Paldang and Puyo, carrying B chromosomes at different frequencies. They were kindly provided by Dr Lee (Seoul National University).

The chromosome number was counted in root tips following fixation in acetic alcohol 1:3 and staining by the Feulgen method.

B chromosome frequencies estimated from chromosome counts of seeds from Korea, which have not been grown in our laboratory before, can be considered the natural frequencies in these populations. These frequencies coincide with those reported with Lee and Lee \& Min loc. cit.

About 150 seeds per population were sown in an experimental field. At anthesis each plot was covered with a thin white cotton fabric to prevent cross-pollination among plots, but allowing openpollination within each one.

Offspring were individually collected in order to count the number of spikes, flowers and grains per plant. From these data, variables with effect on fertility and viability were estimated. For each population the mean number of grains per plant $(G / P)$, grains per spike $(G / S)$, grains per flower $(G / F)$, flowers per plant $(F / P)$, flowers per spike $(\mathrm{F} / \mathrm{S})$ and spikes per plant $(\mathrm{S} / \mathrm{P})$ was estimated. All these variables were obtained in two successive years: in the plants obtained from the seeds from Korea (June 1986) and in the plants of the next generation (June 1987).

In addition, first pollen mitosis was studied in 2B plants. Both the frequency and distribution of Bs at metaphase and the frequency of nondisjunc- 
tion at early anaphase were estimated. Anthers were fixed in acetic alcohol $1: 3$ and stained by the Feulgen method.

\section{RESULTS}

Table 1 shows the frequencies of $\mathrm{B}$ chromosomes in the populations in two generations (1985-86 and 1986-87) both at the time of sowing (November) and harvesting (June). Some of the seedlings died from unknown causes. The observed number of adult plants was compared with the expected number under the assumption that plants with or without Bs survived at random, and $\chi^{2}$ tests were always nonsignificant. The distribution of $\mathrm{Bs}$ in June 1986 and June 1987 were compared by contingency $\chi^{2}$ tests. Since the number of individuals with 1,3 and $4 \mathrm{~B}$ was low, only plants with or without Bs were considered. All tests were nonsignificant.

Tables 2 and 3 show the variables of viability $(\mathrm{F} / \mathrm{P}, \mathrm{F} / \mathrm{S}$ and $\mathrm{S} / \mathrm{P})$ and fertility $(\mathrm{G} / \mathrm{P}, \mathrm{G} / \mathrm{S}$ and $\mathrm{G} / \mathrm{F}$ ) in 1986 and 1987, respectively. Mean values of $F / P$ and $G / P$ were compared by ANOVAS.
Those classes with less than 10 plants were not included in the tests; therefore, only $0 \mathrm{~B}$ and $2 \mathrm{~B}$ plants were considered in Gumsan 3, Gumsan 4 and Paldang, while in Puyo 0B, 2B and 4B plants were compared.

ANOVAS were always nonsignificant at the 0.05 level, with the exception of the variable G/P in Puyo in 1986. However, it can be observed that in all cases the mean number of $G / P$ decreases as the number of $\mathrm{B}$ chromosomes increases. The probability of obtaining this result by chance is $(1 / 2)^{8}$. This is not the case for the variable $F / P$ in which higher or lower values are obtained in plants with or without $\mathrm{B}$ chromosomes. Both variables vary similarly in the two generations. The correlation coefficient for G/P in Puyo between the values of 1986 and 1987 was calculated, being $r=$ $0.99 \pm 0.04$.

It has to be noted that in 4 out of 6 cases, $1 \mathrm{~B}$ plants show the highest values of $\mathrm{G} / \mathrm{P}$. However, these data cannot be statistically analyzed due to the low number of these plants.

Table 4 shows the data of first pollen mitosis of $2 \mathrm{~B}$ plants. At metaphase the frequency of pollen grains with $1 \mathrm{~B}$ was always over 90 per cent. The

Table 1 Distribution of B chromosomes in the populations in 1986 and 1987 at sowing (November) and harvesting time (June)

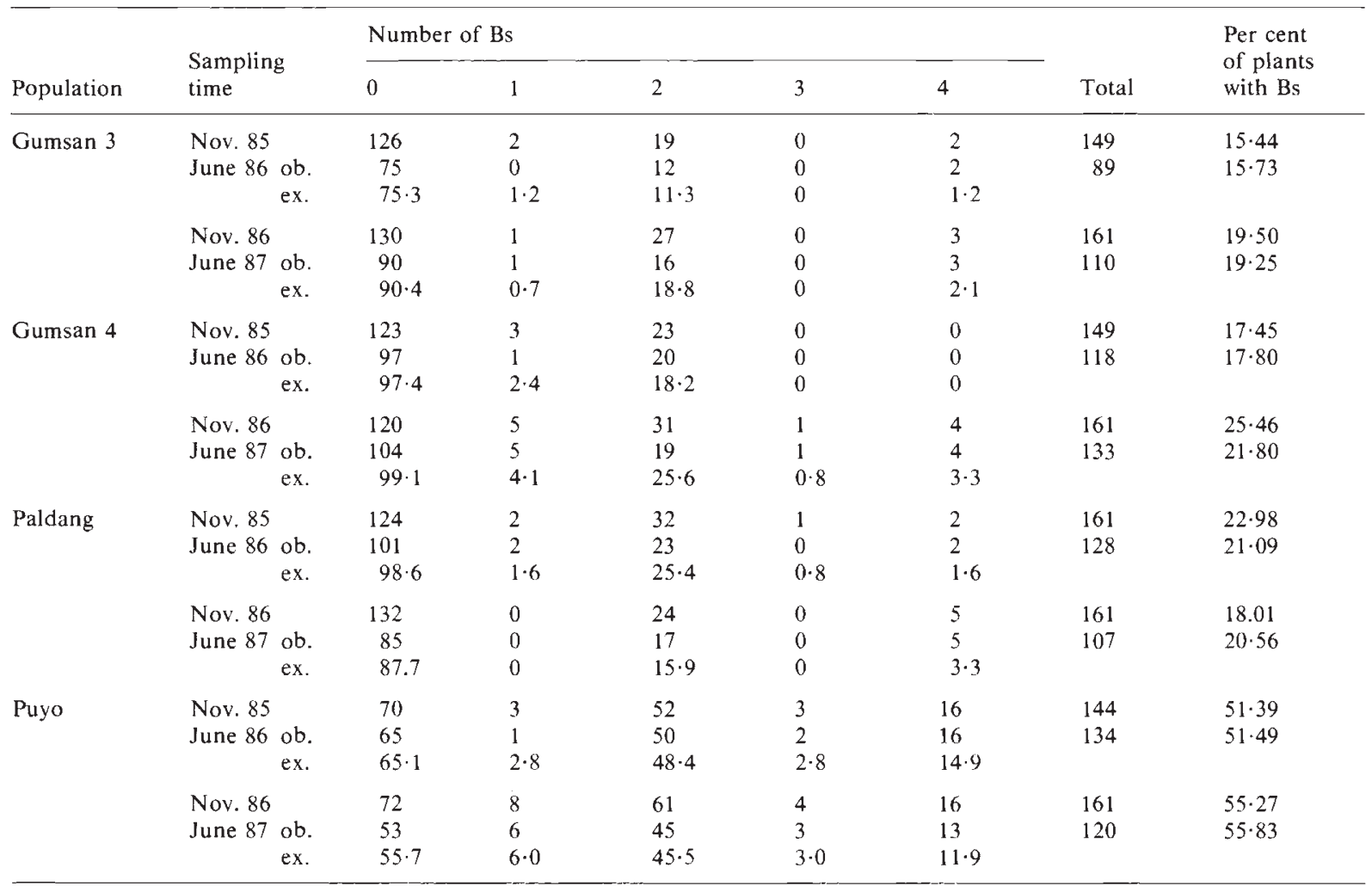


Table 2 Variables of viability and fertility estimated in 1986

\begin{tabular}{|c|c|c|c|c|c|c|c|c|c|c|}
\hline Population & $\begin{array}{l}\text { No. } \\
\text { Bs }\end{array}$ & $\begin{array}{l}\text { No. } \\
\text { Plants }\end{array}$ & $F / P$ & S.D. & $\mathrm{F} / \mathrm{S}$ & $\mathrm{S} / \mathrm{P}$ & $G / P$ & S.D. & $\mathrm{G} / \mathrm{S}$ & $\mathrm{G} / \mathrm{F}$ \\
\hline Gumsan 3 & $\begin{array}{l}0 \\
2 \\
4\end{array}$ & $\begin{array}{r}75 \\
12 \\
2\end{array}$ & $\begin{array}{l}276 \cdot 89 \\
309 \cdot 00 \\
104 \cdot 00\end{array}$ & $\begin{array}{r}231.93 \\
308 \cdot 56 \\
8.00\end{array}$ & $\begin{array}{l}66 \cdot 14 \\
67 \cdot 42 \\
52 \cdot 00\end{array}$ & $\begin{array}{l}4 \cdot 19 \\
4 \cdot 58 \\
2 \cdot 00\end{array}$ & $\begin{array}{c}55 \cdot 16 \\
49 \cdot 08 \\
0\end{array}$ & $\begin{array}{c}51 \cdot 29 \\
40 \cdot 99 \\
0\end{array}$ & $\begin{array}{c}13 \cdot 03 \\
10 \cdot 71 \\
0\end{array}$ & $\begin{array}{l}0 \cdot 20 \\
0 \cdot 16 \\
0\end{array}$ \\
\hline Gumsan 4 & $\begin{array}{l}0 \\
1 \\
2\end{array}$ & $\begin{array}{r}97 \\
1 \\
20\end{array}$ & $\begin{array}{l}203 \cdot 61 \\
160 \cdot 00 \\
202 \cdot 20\end{array}$ & $\begin{array}{c}138 \cdot 67 \\
0 \\
169 \cdot 13\end{array}$ & $\begin{array}{l}68 \cdot 81 \\
53 \cdot 33 \\
66 \cdot 30\end{array}$ & $\begin{array}{l}2 \cdot 96 \\
3 \cdot 00 \\
3 \cdot 05\end{array}$ & $\begin{array}{l}63 \cdot 26 \\
34 \cdot 00 \\
50 \cdot 55\end{array}$ & $\begin{array}{c}60 \cdot 89 \\
0 \\
61 \cdot 28\end{array}$ & $\begin{array}{l}21 \cdot 40 \\
11 \cdot 33 \\
16 \cdot 57\end{array}$ & $\begin{array}{l}0 \cdot 31 \\
0.21 \\
0 \cdot 25\end{array}$ \\
\hline Paldang & $\begin{array}{l}0 \\
1 \\
2 \\
4\end{array}$ & $\begin{array}{r}101 \\
2 \\
23 \\
2\end{array}$ & $\begin{array}{l}266 \cdot 75 \\
712 \cdot 00 \\
231 \cdot 30 \\
220 \cdot 00\end{array}$ & $\begin{array}{c}192 \cdot 63 \\
0 \\
118 \cdot 05 \\
112 \cdot 00\end{array}$ & $\begin{array}{l}74 \cdot 63 \\
83 \cdot 76 \\
67 \cdot 34 \\
62 \cdot 86\end{array}$ & $\begin{array}{l}3 \cdot 57 \\
8 \cdot 50 \\
3 \cdot 43 \\
3 \cdot 50\end{array}$ & $\begin{array}{r}113 \cdot 21 \\
321 \cdot 50 \\
84 \cdot 22 \\
42 \cdot 00\end{array}$ & $\begin{array}{c}107 \cdot 13 \\
0 \\
74 \cdot 55 \\
6.00\end{array}$ & $\begin{array}{l}31 \cdot 67 \\
37 \cdot 82 \\
24 \cdot 52 \\
12 \cdot 00\end{array}$ & $\begin{array}{l}0.42 \\
0.45 \\
0.36 \\
0.19\end{array}$ \\
\hline Puyo & $\begin{array}{l}0 \\
1 \\
2 \\
3 \\
4\end{array}$ & $\begin{array}{r}65 \\
1 \\
50 \\
2 \\
16\end{array}$ & $\begin{array}{l}197 \cdot 17 \\
242 \cdot 00 \\
173 \cdot 92 \\
187 \cdot 00 \\
125 \cdot 13\end{array}$ & $\begin{array}{c}120 \cdot 85 \\
0 \\
109 \cdot 67 \\
63.00 \\
60.65\end{array}$ & $\begin{array}{l}70 \cdot 81 \\
60 \cdot 50 \\
72 \cdot 47 \\
74 \cdot 80 \\
66 \cdot 73\end{array}$ & $\begin{array}{l}2 \cdot 78 \\
4 \cdot 00 \\
2 \cdot 40 \\
2 \cdot 50 \\
1 \cdot 88\end{array}$ & $\begin{array}{l}60 \cdot 86 \\
40 \cdot 00 \\
46 \cdot 74 \\
64 \cdot 00 \\
13 \cdot 12\end{array}$ & $\begin{array}{c}42.97 \\
0 \\
33.62 \\
13.00 \\
43.06\end{array}$ & $\begin{array}{r}21 \cdot 86 \\
10 \cdot 00 \\
19 \cdot 48 \\
12 \cdot 80 \\
7 \cdot 00\end{array}$ & $\begin{array}{l}0.31 \\
0 \cdot 17 \\
0 \cdot 27 \\
0 \cdot 34 \\
0 \cdot 10\end{array}$ \\
\hline
\end{tabular}

$\mathrm{F} / \mathrm{P}=$ flowers per plant, $\mathrm{S} . \mathrm{D} .=$ standard deviation, $\mathrm{F} / \mathrm{S}=$ flowers per spike, $\mathrm{S} / \mathrm{P}=$ spikes per plant, $\mathrm{G} / \mathrm{P}=\mathrm{grains}$ per plant, $\mathrm{G} / \mathrm{S}=$ grains per spike, $G / F=$ grains per flower.

Table 3 Variables of viability and fertility estimated in 1987

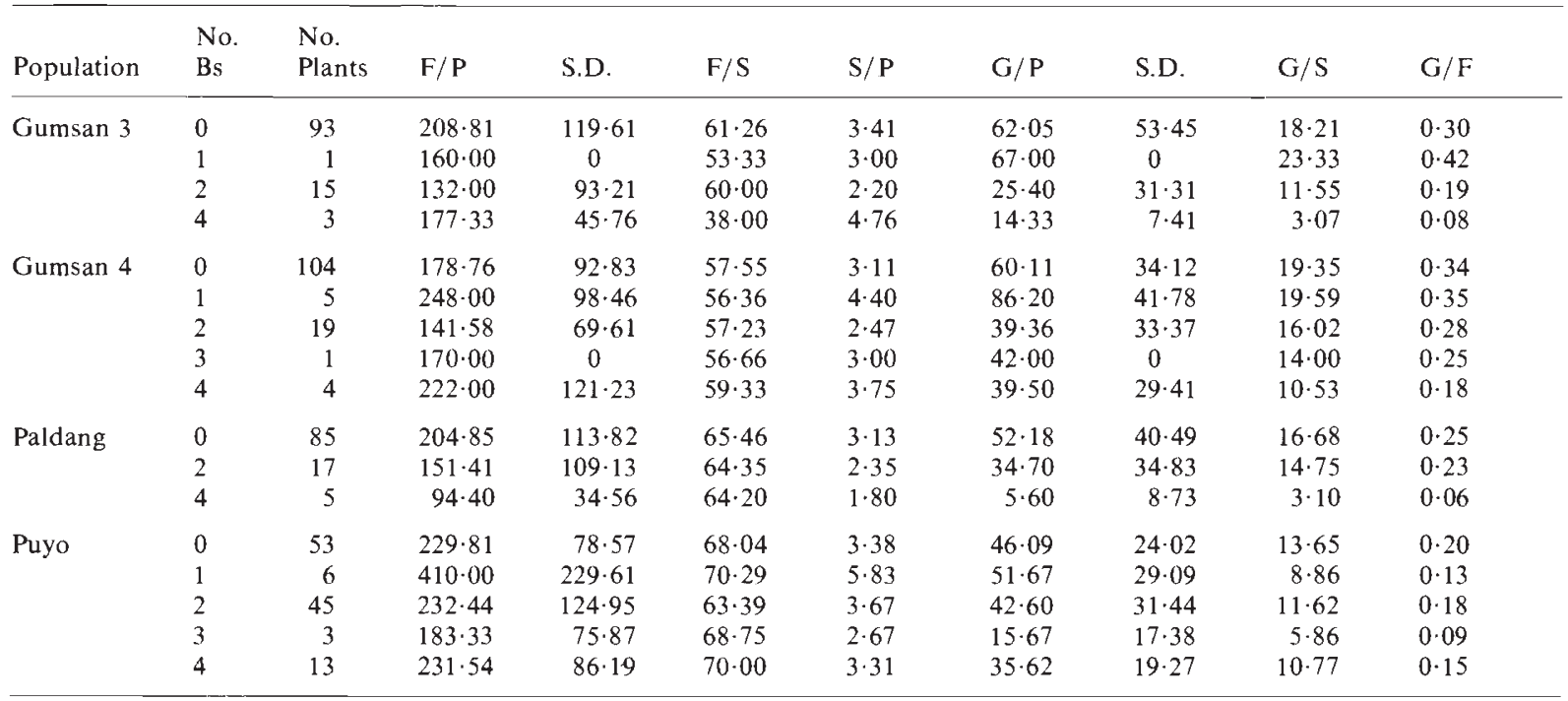

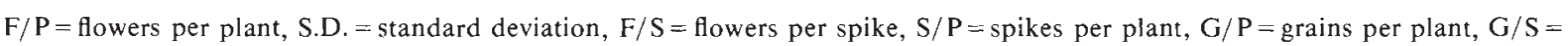
grains per spike, $\mathrm{G} / \mathrm{F}=$ grains per flower.

Table 4 Cytological behaviour of $2 \mathrm{~B}$ plants at first pollen mitosis

\begin{tabular}{|c|c|c|c|c|c|c|c|}
\hline \multirow[b]{2}{*}{ Population } & \multirow{2}{*}{$\begin{array}{l}\text { No. } \\
\text { Plants }\end{array}$} & \multicolumn{3}{|c|}{ Metaphase } & \multirow{2}{*}{$\begin{array}{l}\text { Total of } \\
\text { cells }\end{array}$} & \multirow{2}{*}{$\begin{array}{l}\text { Frequency of } \\
\text { nondisjunction }\end{array}$} & \multirow{2}{*}{$\begin{array}{l}\text { Total of } \\
\text { cells }\end{array}$} \\
\hline & & $\mathrm{OB}$ & $1 \mathrm{~B}$ & $2 \mathrm{~B}$ & & & \\
\hline Gumsan 3 & 5 & 1 & 96 & 3 & 100 & 0.95 & 73 \\
\hline Gumsan 4 & 5 & 0 & 95 & 5 & 100 & 0.98 & 61 \\
\hline Paldang & 5 & 6 & 90 & 4 & 100 & 0.98 & 55 \\
\hline Puyo & 5 & 3 & 97 & 0 & 100 & 0.93 & 42 \\
\hline
\end{tabular}


frequency of nondisjunction estimated at early anaphase was always over 93 per cent. The similarity of these results among populations is evident. Micronuclei were observed in pollen grains from first interphase to telophase with a very variable frequency ( 0 to 50 per cent) depending on particular anthers and irrespective of the population.

\section{DISCUSSION}

B chromosome frequency and distribution was maintained in the four Korean populations in two successive generations irrespective of the environmental change from Korea to Madrid. Therefore, it seems that a stable polymorphism for B chromosomes can be established at different frequencies and also, that environment is not a main influence on the maintenance of the polymorphism. This result is in contradiction with that of Jones and Rees (1982) who found a continuous increase in the percentage of plants with Bs over six generations in one Korean line. In our experiment the variation in the percentage of plants with Bs between generations was under 4 per cent in three populations and was 8 per cent in Gumsan 4 . In addition, the distribution of Bs was maintained in all cases, as demonstrated by $\chi^{2}$ contingency tests comparing the distribution of $\mathrm{Bs}$ in adult plants in 1986 and 1987.

The ANOVAS made for comparing the variables $\mathrm{F} / \mathrm{P}$ and $\mathrm{G} / \mathrm{P}$ were always nonsignificant with the exception of the variable $G / P$ in Puyo in 1986. However, in our experiment the power of the test is low due to the large variances observed in all cases (tables 2 and 3 ).

The results obtained for the variables of viability $(\mathrm{F} / \mathrm{P}, \mathrm{F} / \mathrm{S}$ and $\mathrm{S} / \mathrm{P})$ suggest that $\mathrm{B}$ chromosomes do not influence the number of spikes or flowers per plant. It can be observed (tables 2 and 3 ) that there is no relationship between the number of $\mathrm{F} / \mathrm{P}$ and the number of Bs. This is true when we compare both the results of different populations in the same generation, or the same population in different generations. For example, in Gumsan $3,2 \mathrm{~B}$ plants formed more $\mathrm{F} / \mathrm{P}$ than $\mathrm{OB}$ ones in 1986, while they formed less in 1987. Similar results were also found in the lines JNK and Charito (Puertas et al., 1985).

On the contrary, $\mathrm{B}$ chromosomes do influence fertility. There is a decrease of the number of $G / P$ as the number of $B$ s increases from 0 to 2 to 4 (tables 2 and 3 ). In all cases $2 \mathrm{~B}$ plants formed less $\mathrm{G} / \mathrm{P}$ than $\mathrm{OB}$ ones. It is very improbable that this result was obtained by chance. ANOVAS were nonsignificant; however, it is possible that a type II error was made in this case, due to the large variance of this variable. It is also remarkable how similar the data are between both generations.

A decrease in fertility when the number of Bs increases was also observed by Müntzing (1963) and Puertas et al. (1985) in other rye varieties.

These results cannot be explained under the hypothesis of the adaptive nature of $\mathrm{B}$ chromosomes. The effect of Bs was not beneficial for any of the variables analyzed. Their effect was neutral both in relation to survival and to the formation of flowers and spikes, while it was harmful in relation to fertility.

$1 \mathrm{~B}$ plants formed more $\mathrm{G} / \mathrm{P}$ than $\mathrm{OB}$ ones in some cases. However, this result has to be considered with caution. The frequency of $1 \mathrm{~B}$ plants in any population is always very low, due to the mechanism of transmission of the Bs which tends to transmit them in even numbers. Therefore, even accepting that $1 \mathrm{~B}$ plants are really more fertile, their effect at the population level would be negligible, due to their low frequency and to the fact that most of their offspring consist of $0 \mathrm{~B}$ and $2 \mathrm{~B}$ individuals (Puertas and Lacadena, 1974).

The cytological behaviour of B chromosomes at first pollen mitosis in $2 \mathrm{~B}$ plants was similar in all populations. It has to be noted that the number of B chromosomes present at first pollen metaphase is a direct indication of the behaviour of $\mathrm{B}$ chromosomes at meiosis. Therefore, since most metaphases showed 1B (table 4) it can be deduced that Bs segregated quite regularly and that few B univalents were lost. Some Bs were lost as micronuclei, but this phenomenon occurred sporadically in some anthers and was not specific of any population. The fact that the rate of nondisjunction was close to 95 per cent in all cases, as in other rye populations (Matthews and Jones, 1983) indicates the stability of this important mechanism for the maintenance of $\mathrm{B}$ chromosomes.

It has been repeatedly argued by many authors that the polymorphism for B chromosomes is maintained by a balance between their tendency to increase in number due to nondisjunction, and the decrease of fertility in individuals with a high number of Bs (see Jones and Rees, 1982 for a review). Matthews and Jones (1983) estimated parameters influencing $B$ chromosome transmission and applied the values to a computer simulation model. They found that adjustment of equilibrium levels was effectively brought about by variation in the nonpairing rate and the nonpaired loss rate parameters, rather than through fluctuations in nondisjunction and direction rate 
parameters which are always high and only slightly variable. They then concluded that three main factors appear to influence B polymorphisms: the accumulation mechanism, instabilities in the inheritance of Bs (i.e., pairing behaviour at meiosis), and the adverse effects upon fitness.

In our experiment the frequency of plants with Bs was about 20 per cent in three populations and it was over 50 per cent in Puyo. However, all these parameters were similar in all populations; therefore, it seems that none of them by itself can account for the establishment of B chromosome balanced polymorphism at a given frequency. It is possible that $\mathrm{B}$ chromosomes can be maintained at a wide range of frequencies provided the tendency to B loss and the low fitness of plants carrying $\mathrm{Bs}$ is compensated by a sufficient proportion of gametes carrying Bs formed in each generation.

It should be considered, although it seems paradoxical, that the loss of $\mathrm{B}$ chromosomes due to instabilities during meiosis and pollen mitosis, and the low fertility of plants with many Bs, are not harmful for Bs themselves, but rather that they are necessary mechanisms to compensate for the excess of B chromosomes produced by nondisjunction. Therefore, the apparent failures of B segregation during gametogenesis, which have been regularly observed in all populations, are probably established properties of the B chromosome genetic system and necessary for their maintenance at moderate frequencies. If some Bs were not lost, and nondisjunction occurred in 100 per cent of the cases, too many Bs would be produced and their effect would be too deleterious for the population. It seems evident that the decrease of fertility is the main influence of B chromosomes on phenotype; so that a too high frequency of $\mathrm{B}$ chromosomes would produce a decrease of the fitness of the population which probably would lead to its extinction.

Acknowledgements This work was supported by a grant from the Comisión Asesora de Investigación Científica y Técnica of Spain.

\section{REFERENCES}

HÅKANSON, A. 1948. Behaviour of accessory chromosomes in the embryo sac. Hereditas, 34, 35-39.

JONES, R. N. AND REES, H. 1982. B Chromosomes. Academic Press, London.

LEE, W. J. 1963. Frequency and geographical distribution of rye (Secale cereale) with accessory chromosomes in Korea. Preliminary report. Kor. J. Bot. 6, 15-17.

LEE, W. J. 1966. On accessory chromosomes in Secale cereale. III. Relationship between the frequency of accessory chromosomes in rye and soil properties. Kor. J. Bot. 9, 33-38.

LEE, W. J. 1976. Frequency of rye (Secale cereale) with B chromosomes in Yechon Area. Kor. J. Breeding 8, 153-155.

LEE, W. J. 1981. Frequency of B chromosomes in rye (Secale cereale) cultivated in Paldang. Kor. J. Bot. 24, 181-190.

LEE, W. J. AND MIN, B. R. 1965. On accessory chromosomes in Secale cereale. I. Frequency and geographical distribution of plants with accessory chromosomes in Korea. Kor. J. Bot. 8, 41-46.

LEE, W. J. AND MIN, B. R. 1966. Frequency and geographical distribution of rye with accessory chromosomes in Korea. Wheat Inf. Ser. 21, 27-29.

LEE, W. J. AND MIN, B. R. 1968. On accessory chromosomes in Secale cereale. IV. Further study on frequency and geographical distribution of rye with accessory chromosomes in Korea. Kor. J. Bot. 11, 71-75.

MATTHEWS, R. B. AND JONES, R. N. 1983. Dynamics of the B chromosome polymorphism in rye. II. Estimates of parameters. Heredity, 50, 119-137.

MÜNTZING, A. 1946. Cytological studies of extra fragment chromosomes in rye. III. The mechanism of non-disjunction at the pollen mitosis. Hereditas, 32, 161-180.

MÜNTZING, A. 1954. Cytogenetics of accessory chromosomes (B-chromosomes). Caryologia, Vol. Suppl. 6, 282-301.

MÜNTZING, A. 1957 . Frequency of accessory chromosomes in rye strains from Iran and Korea. Hereditas, 43, 682-685.

MÜNTZING, A. $1957 \mathrm{~b}$. Frequency of accessory chromosomes in rye from Korea. Wheat Inf. Ser., 5, 16-18.

MÜNTZING, A. 1963. Effects of accessory chromosomes in diploid and tetraploid rye. Hereditas, 49, 371-426.

PUERTAS, M. J. AND LACADENA, J. R. 1974. The transmission of rye B chromosomes in natural pollination. Theor. Appl. Genet., 45, 197-204.

PUERTAS, M. J., ROMERA, F. AND DE LA PEÑA, A. 1985. Comparison of $\mathrm{B}$ chromosome effects on Secale cereale and Secale vavilovii. Heredity, 55, 229-234. 